\title{
PRAKTIK EKOWISATA DI KAMPUNG TRADISIONAL BENA, DESA TIWORIWU KABUPATEN NGADA, PROVINSI NUSA TENGGARA TIMUR
}

\author{
Muni Imelda Amtiran a, 1, Ida Bagus Suryawan a, 2 \\ 1imeldamuniamtiran@gmail.com,2 inigusmail@yahoo.com \\ a Program Studi S1 Destinasi Pariwisata,Fakultas Pariwisata,Universitas Udayana, Jl. Dr. R. Goris, Denpasar, Bali 80232 Indonesia
}

\section{ABSTRACT}

The participation of local community is very needed in practicing ecotourism at Bena traditional village to support their ecotourism development. Ecotourism is an alternative tourism that has advanced and nature base by focus and experience on nature along with giving the lowest impact on the environment. Based on the statement above this research is important to be done in order that environment conservation and their culture be still maintained by the local community besides it becomes an example of model or example for the other village. It also becomes a source of income that can improve the local community economic of Bena traditional village. The method that used to colect the data in this study was observation method, interviewing method and documentation. The data was used qualitative and quantitative by data source, primary and secondary data. Purposive sampling technique was used to get the information from informant determaining and data analysis is used qualitative descriptive by ecotourism practice concept approach. The result of this study showed that the local community kept their nature conservation in practicing ecotourism in Bena village. The local community developed their ecotourism dominantly as one of activity tourism in Bena.

Key words: Ecotourism, local community, development.

\section{PENDAHULUAN}

Dalam pengembangan ekowisata di Kampung Tradisional Bena sangat dibutuhkkan partisipasi masyarakat lokal untuk mendukung pengembangan ekowisata di daerah. Ekowisata yaitu contoh wisata alternatif yang mempunyai tingkat interaksi yang tinggi antara masyarakat lokal dengan wisatawan (Arida, 2009).

Berdasarkan hal tersebut diatas maka penelitian ini penting untuk dilakukan agar praktik ekowisata yang dilakukan oleh masyarakat lokal agar tetap dipertahankan kelestarian lingkungan dan budayanya dapat dijadikan sebagai contoh atau teladan bagi desa yang lain, juga sebagai salah satu sumber pendapatan bagi masyarakat serta meningkatkan perekonomian masyarakat lokal Kampung Tradisional Bena. Penelitian ini beranjak dari rumusan masalah yaitu bagaimana praktik ekowisata di Kampung tradisional Bena, Desa Tiworiwu, Kabupaten Ngada? Tujuan dari penelitian ini adalah untuk mengetahui sejauhmana praktik ekowisata di kampung tradisioanal Bena. Diharapkan dapat bermanfaat untuk menambah wawasan bagi mahasiswa, dan bagi masyarakat lokal dapat bermanfaat untuk menjaga kelestarian alam dan budaya, mengurangi pengangguran masyarakat lokal serta bagi pemerintah menambah pendapatan daerah.

\section{METODOLOGI PENELITIAN}

Metode pengumpulan data yang digunakan metode observasi, wawancara mendalam dan dokumentasi. Jenis data yang digunakan yaitu data kualitatif dan kuantitatif diperoleh dari sumber data, baik data primer maupun sekunder. Untuk memperoleh informasi digunakan penentuan informan pangkal dan informan kunci. Analisis data yang digunakan yaitu deskriptif kualitatif dengan pendekatan dan konsep Tri Ning Tri, konsep ekowisata.

Konsep Tri Ning Tri disini membanding tiga tipe penggerak ekowisata yang dominan, dibagi dalam tipe pemerintah, tipe investor, dan tipe masyarakat (Arida, 2014). Konsep praktik ekowisata menurut Quebec dan Fenel mengatakan bahwa dalam praktik ekowisata menggunakan prinsip pariwisata berkelanjutan dimana secara aktif menyumbang konservasi alam dan budaya, melibatkan masyarakat lokal dalam setiap kegiatannya, dilakukan dalam bentuk skala kecil (Arida, 2009).

Ekowisata merupakan wisata berbasis alam yang berkelanjutan dengan fokus pengalaman dan pendidikan tentang alam, dikelola dengan sistem pengelolaan tertentu dan memberi dampak negatif paling rendah terhadap lingkungan, tidak bersifat konsumtif dan berorientasi pada lokal (dalam hal kontrol, manfaat yang dapat diambil dari kegiatan usaha) dalam Arida (2009). 
Ekowisata berbasis masyarakat merupakan usaha ekowisata yang menitikberatkan peran aktif komunitas. Hal itu didasarkan pada kenyataan bahwa masyarakat memiliki pengetahuan tentang alam serta budaya yang menjadi potensi dan nilai jual sebagai daya tarik wisata, sehingga pelibatan masyarakat menjadi mutlak. Pola ekowisata berbasis masyarakat mengakui hak masyarakat lokal dalam mengelola kegiatan wisata di kawasan yang mereka miliki secara adat ataupun sebagai pengelola (Arida, 2009). Penulisan ini terfokus pada praktik ekowisata di Kampung Tradisional Bena.

\section{HASIL DAN PEMBAHASAN}

\subsection{Lokasi Penelitian}

Kampung Tradisional Bena terletak di Desa Tiworiwu Kecamatan Jerebu'u, $18 \mathrm{~km}$ arah selatan dari Kota Bajawa, Kabupaten Ngada. Terletak di Gunung Inerie dengan ketinggian 2.245mdpl (Sumber: Dinas P2KI, Kabupaten Ngada). Kampung Tradisional Bena adalah salah satu dari desa tradisional di Flores yang masih tersisa meninggalkan jejak budaya megalitik, seperti yang dapat dilihat di Gambar 3.1.

\section{Gambar 3.1 Kondisi Kampung Tradisional Bena}

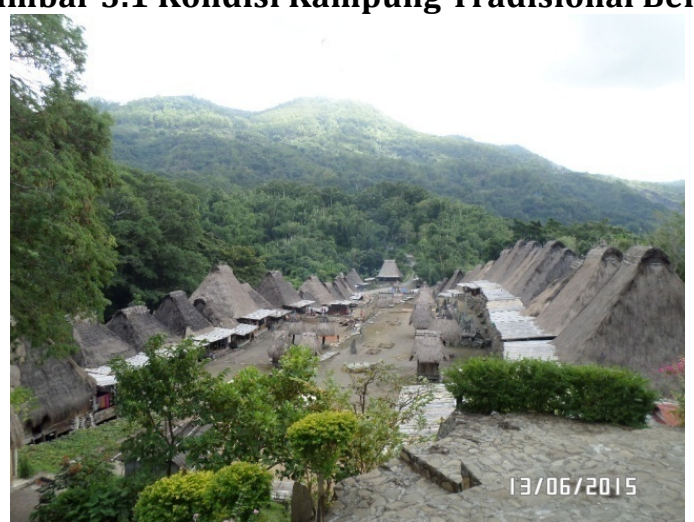

Sumber: Penelitian (2015)

\subsection{Praktik Ekowisata di Kampung Tradisional Bena, Desa Tiworiwu, Kabupaten} Ngada.

Masyarakat kampung Bena sangat menjaga lingkungannya terlihat dari upacara penebangan pohon untuk membangun rumah adat. Sebelum menebang pohon ketua adat melakukan acara ritual untuk meminta izin kepada leluhur yaitu dengan upacara potong ayam dan setelah menebang pohon masyarakat setempat melakukan penanaman kembali dengan anakan pohon yang sudah disiapkan oleh masyarakat setempat. Dan budaya masyarakat Bena dari dulu hinga sekarang tanah tidak boleh dijual dan hak tanah merupakan warisan para leluhur.
Pola ekowisata berbasis masyarakat yang ada di Bena adalah pola pengembangan ekowisata memberikan keterlibatan penuh oleh masyarakat setempat dalam perencanaan, pelaksanaan, dan pengelolaan usaha ekowisata dan segala keuntungan yang diperoleh. Dalam hal perencanaan masyarakat lokal dalam hal ini pengelola yang dipercayakan oleh masyarakat setempat untuk merencanakan kegiatan wisata khususnya di Kampung Bena dan dalam pelaksanaan serta pengelolaan usaha ekowisata dilakukan secara bersama dengan masyarakat kampung Bena.

Ekowisata berbasis masyarakat yang ada di kampung Bena sudah menciptakan kesempatan kerja bagi masyarakat setempat, dan mengurangi kemiskinan, di mana penghasilan dari kegiatan ekowisata tersebut adalah berasal dari jasa-jasa wisata, homestay, menjual kerajinan seperti hasil kain tenun ikat dan pembagian kotak donasi yang dibuka setiap tiga bulan sekali. Dengan kata lain ekowisata sebagai bentuk industri pariwisata berbasis lingkungan yang memberikan dampak kecil bagi kerusakan alam dan budaya lokal sekaligus menciptakan peluang kerja dan pendapatan, serta membantu kegiatan konservasi alam itu sendiri.

Dengan adanya praktik ekowisata yang ada di kampung Bena perekonomian masyarakat lokal cukup meningkat, hal ini dilihat dari hasil tenunan ikat yang dibeli wisatawan, serta pendapatan yang didapat dari selama wisatawan menginap dan tentunya dari hasil perkebunan mereka sendiri yang dijual ke pasar. Kegiatan ekowisata yang terjadi di kampung tradisional Bena membawa dampak positif terhadap pelestarian lingkungan dan budaya asli setempat yang pada akhirnya diharapkan akan mampu menumbuhkan jati diri dan rasa bangga antar penduduk setempat yang tumbuh akibat peningkatan kegiatan ekowisata.

Secara keseluruhan, pengembangan ekowisata di Bena sudah mampu meningkatkan kualitas hubungan antar masyarakat yang satu dengan yang lainnya, meningkatkan kualitas hidup masyarakat setempat dan selalu menjaga lingkungannya. Oleh karena itu pelibatan masyarakat Bena menjadi mutlak, mulai dari tingkat perencanaan hingga pada tingkat pengelolaan.

Dengan mengenal ekowisata wisatawan dan masyarakat Bena dapat ditingkatkan kesadaran 
serta apresiasinya terhadap alam, nilai-nilai peninggalan sejarah dan budaya lokal. Masyarakat di Kampung Bena merupakan penggerak paling dominan dibandingkan pemerintah dan investor. Kegiatan ekowisata yang ada di Bena dirintis dan dikelola secara mandiri oleh masyarakat lokal, namun tetap dibantu oleh pihak luar (tokoh atau LSM).

Budaya seperti itu sampai sekarang terlihat masih dilakoni oleh masyarakat Bena itu sendiri. Terlihat dari pembangunan rumah adat setiap suku saling bergotong royong membantu baik dalam upacara adat, penebangan pohon sampai penanaman tiang rumah adat dan pemasangan atap masyarakat kampung Bena bersama-sama dan saling membantu baik dalam hal tenaga maupun dana. Dalam hal dana, setiap suku memberikan hewan untuk disembelih sebagai korban upacara maupun sebagai bahan makanan selama pembangunan rumah adat dikerjakan.

Disamping itu juga pemerintah tidak banyak ikut campur dalam hal pengelolaan, peran pemerintah dalam hal ini hanya sebagai fasilitator dan regulator seperti mempromosikan Bena, memperbaiki infrastruktur jalan, mengatur kerja sama dengan pihak LSM maupun travel agent namun dalam hal pengambilan keputusan masyarakat serta pengelola kampung Bena itu sendiri. Kampung Bena sendiri bekerja sama dengan pihak LSM yaitu Swiss Contact dan INDECON. Lembaga ini bekerja sama dalam hal pelatihan seperti Bahasa Inggris, pembuatan kain tenun dari pewarnaan alam. Sedangkan lembaga adat seperti Kelompok Mai Masa (pengrajin tenun ikat), Kelompok Pembangunan Rumah Adat, Kelompok Tanda Musik Rakyat, Kelompok Sadar Wisata dan FPPD.

Pendapatan langsung dikelola oleh pihak pengelola Bena. Tradisi yang ada di sana masih sangat kuat dan sangat mandiri. Sistem pembukaan kotak donasi pun yaitu secara bersama-sama yang dihadiri oleh ketua adat kampung Bena, ketua dari 9 suku, pengelola, kepala desa dan perwakilan masyarakat lokal, kotak donasi dibuka setiap tiga bulan sekali. Setiap pendapatan kotak donasi dibagi dalam empat pembagian yaitu 50\% dikhususkan untuk pelestarian kubur megalit, pembangunan rumah adat baik itu renovasi murni maupun setengah renovasi (seperti ganti atap), 20\% dibagi untuk pengurus/ pengelola termasuk 9 ketua suku/ aparatur desa, 20\% untuk PAD Desa dan 10\% dikhususkan untuk Pemerintah Daerah dalam hal ini Dinas Perhubungan, Pariwisata, Komunikasi dan Informatika (P2KI) Kabupaten Ngada.

(Sumber: Emiliana Kopa, sekretaris pengelola kampung Bena)

\section{PENUTUP}

\subsection{Simpulan}

Praktik Ekowisata di Kampung Tradisional Bena, Desa Tiworiwu, Kabupaten Ngada meliputi: masyarakat Bena sudah aktif menjaga alam dan budaya, kegiatan pariwisata melibatkan masyarakat Bena serta memberikan sumbangan positif terhadap tingkat kesejahtraan masyarakat lokal, sudah dilakukan dalam bentuk wisata skala kecil dan bentuk kegiatannya adalah berbasis lingkungan dimana memberikan dampak kecil bagi kerusakan alam dan menciptakan peluang kerja serta pendapatan bagi masyarakat lokal, Bena sudah menjadi pusat kegiatan yang berbasis alam yang berkelanjutan dimana dapat meberi pengalaman, pendidikan tentang alam serta sudah dikeloalh secara sederhana dan memberikan dampak negatif yang rendah terhadapa lingkungan, masyarakat menjadi aspek penggerak paling dominan di Bena.

\subsection{Saran}

1. Sikap masyarakat Bena diharapkan tetap dipertahankan untuk menjaga dan melestarikan alam dan budayanya, tidak terpengaruh dengan dunia luar dan sikap keramahtamahan, gotong royong, nilai-nilai budaya luhur tetap dipertahankan dan Pemerintah Kabupaten Ngada tetap sebagai fasilitator dan regulator serta mengontrol perkembangan pariwisata di Bena khususnya dalam hal pendampingan dan pembinaan terhadap masyarakat lokal.

2. Dalam praktik ekowisata di Bena diharapkan masyarakat tetap dominan dan aktif dalam memberikan sumbangan positif untuk melestarikan alam dan budaya.

\section{DAFTAR PUSTAKA}

Arida, Nyoman Sukma. 2009. Meretas Jalan Ekowisata Bali Denpasar: Udayana University Press.

Arida, Nyoman Sukma. 2014. Dinamika Ekowisata TRI NING TRI Di Bali (Proses Perkembangan Produk, Pelibatan Masyarakat, dan Strategi Pengembangan. Yogyakarta: Universitas Gadjah Mada.

Dinas Perhubungan, Pariwisata, Komunikasi, dan Informatika (P2KI) Kabupaten Ngada. 2015. Data Kepariwisataan Ngada. Dinas P2KI Ngada. 